\title{
Editorial: Home Support - A Fragile Structure Indeed
}

In this issue are four articles that focus on services designed to maintain elderly persons within their communities. The stimulus for these papers was a symposium sponsored by this journal at the 1997 Canadian Association on Gerontology meetings in Calgary, the theme of which was supporting community support services. At the time of the symposium, and later as I discussed these papers with the authors, I again reflected on how community is a concept that is often invoked but seldom specified. Furthermore, in the atmosphere of economic efficiency that has characterized the restructuring of health services across the country, arguments for social justice are more likely today to invoke accusations of being an ideologue than seriously considered as a goal of social policy. For instance, the mixed economy of care which positions users as consumers rather than citizens is now a fait accompli both nationally and internationally. Yet assessments of its effects are difficult to find. It is assumed that such a model is efficient and hoped that it is also effective. Granted, documenting policy outcomes is always contestable. Policy impacts are multi-dimensional and a writer's choice of indicators can easily be challenged. Nevertheless, this is precisely the challenge taken up in the studies that make up the special section of this issue.

Readers will note that the authors of these articles bring a critical perspective to their research questions, conceptual frameworks used and research designs chosen - the essential ingredients of methodology. By a critical perspective I mean that they engage with theory in a way that challenges the way things are, enabling research to become a catalyst for transforming current policy and practice. Thus, I wish to highlight the research strategies used by the authors. Many of these designs would be lumped into a category titled "qualitative methods". To do so would belittle the analytical frameworks as well as the creativity that is reflected here. Each author was faced with the task of documenting policy effects that are not reflected in readily available data sets. Each was successful in capturing some of these effects. For instance, the different types of stress-related injuries experienced by service staff (see Denton et al.) result in lost productivity.

This issue of the journal appears at a time when aging Canadians are receiving mixed messages about the future of long-term care. The latter has always been the poor cousin in health care allocations. Health care is a provincial responsibility in Canada; however, the federal government has historically taken leadership in key areas of legislation, such as the 
Canada Health Act. Over the last decade the federal role has become quite passive, causing concern that provincial disparities will increase even more in the future. Recently, one might argue, there seems to be a rethinking of federal leadership in long-term care. The start of the change was signalled in the calling of a National Forum on Health - the recommendations of which Steven Lewis (a member) addressed at the 1997 Calgary symposium. Subsequently, there has been the development of national conferences on Pharmacare, Health Information Systems and Home Care (Health Canada, 1998a, b, c) and the subsequent pursuit of some of their recommendations through the Health Transition Fund. These initiatives have retrieved the idea of a national long-term care policy from the dustbin of possibilities that was its fate during the years that deficit reduction was the dominant policy discourse (Neysmith, 1995).

Unfortunately, community support services remain the poor cousin in a mixed economy of care where the emergence of market models threatens those whose economic position makes them vulnerable. The vulnerability of several players in the community care drama comes through in each paper. There is the obvious precariousness of the recipient of services. However, the vulnerability of their spouses (O'Connor), home care office workers as well as managers (Denton et al.), personal care workers (Keigher) and the agencies repositioning themselves in the contract system (Williams et al.) is also evident. All of these articles, either directly or indirectly, take up the problematic idea of equating users of community based services with market consumers. They challenge the idea that long-term care services are a commodity wherein elderly people and their carers have the necessary product information to make informed choices. In fact, these very different pieces of research suggest that assuming such images to be false might be closer to the mark. These studies document several aspects of services that can facilitate or impede the efforts of elderly people to thrive and not just survive in their homes.

The paper by Paul Williams et al. discusses, using key informant and focus group data, the Ontario process of introducing managed care. Important issues for consumers, providers and policy makers emerge. As he concludes, it is indeed worrisome that the process and the assumptions that competition will result in quality as well as cost savings have not stirred more public debate than there has been. Certainly the experiences of Olsten in Manitoba (Shapiro, 1997) and Comcare in Kingston that he cites are consistent with experiences in other jurisdictions. I juxtapose the questions raised by Williams et al. with recent events in New Zealand where managed competition was introduced into the community health sector in the early nineties. In examining the conditions that lead to massive protests in 1997 and the modification of the model, Aston (1999, p. 145) notes that: "Because contracting involves negotiating, designing and monitoring contracts, any system will have higher visible transaction costs than a system in which decisions are made internally. . . Reasons 
for this include the additional layers of bureaucracy required to support the contracting process; the poor state of of information systems when contracting was first introduced; the legalistic approach to contracting, and hence the tendency towards complete specification of all obligations; the financial environment, with its gap between the (regional Health Authorities) revenues and the costs of service provision; and the adversarial relationships between purchasers and providers. ... The result was that the years following the introduction of a market oriented health system were characterized by conflicting interests and cultures, a tendency toward secrecy, adversarial relationships and constant change. Through all of this the performance of the health care sector remained poor."

This quote suggests that Ontario has seen the future of its current policy direction and it is foreboding. Thus, Williams may be overly optimistic in his conclusion about documenting the effects of managed care. Documenting takes time - a very scarce resource. Will the CCACs be able to do so? Will they want to?

Margaret Denton and associates examine occupational health issues for personnel at various levels in the community care system. Hospital restructuring has resulted in rapidly increasing client numbers for home care agencies due to early discharge of seriously ill patients. The stress employees are experiencing is costly but not normally calculated into service budgets. The issues raised in this paper can be responded to in a variety of ways. Individual agencies can, and do, modify their work milieus. Programs can be mounted to help employees deal with and manage stress. However, these are basically ways of coping with a situation. The types of changes needed to ensure that working conditions do not exacerbate what are already demanding jobs lie at the level of provincial and federal policy. Working conditions will not improve until the funding and organizational issues discussed above are addressed.

Sharon Keigher documents the United States experience in one city which is using a consumer model of care known as direct payment. On the surface there appear to be attractive features to this model which puts dollars into the hands of service users. There is a dark underside, however, and it is that choice is virtually absent for lower income elders, their families and indeed the personal care workers they employ. The latter can determine the hours and for whom they work. However, low hourly wages, lack of benefits and the need to maintain the goodwill of employers resonate more with the conditions of classic domestic service than they do with that of a free lance worker. The greatest benefits seem to accrue to upper income elders. Furthermore, one might ask if any of these players have access to the range of information that underlies a market model? The experiences presented in this study suggest that important knowledge was frequently absent. Also, as elders and their families make these choices, are there feasible alternatives available to them? A market model assumes that services exist. An important finding in this study is that they frequently 
do not. One is reminded of employment policies that emphasize training. The diagnosis is that workers lack skills when the problem is a lack of secure full-time jobs. A similar dynamic seems to be operating in this home care model.

Deborah O'Connor focusses on those who are not using the service system. Her in-depth interviews with spouse carers raise another dimension of what community support programs are about. Providers usually think of need in categories that relate to services that may be available. O'Connor questions this connection and the static model associated with it. Perhaps even more importantly she outlines how the caring experience is constructed from discourses that are available to participants. This dynamic portrayal not only repositions our understanding of non-service users but challenges prevailing models about the content and organization of services. In some ways this is the most optimistic study in this collection. It highlights, to use O'Connor's phrase, possibilities for (re)storying support. As she demonstrates, people are not fixed in their identities, they not only change but at any moment can hold quite contradictory views of their situation. People do take up alternative discourses but these have to be available to them for that to happen. However, if an individual is seen only as a caring spouse, then needs outside of this professional definition will not be recognized as legitimate.

All four studies underline the complexity of policy effects. There are a variety of players in a community based care system and there is no reason to believe that they will experience, and thus respond, in one voice to any policy. As service providers try to reposition themselves in the mixed economy of care that prevails today their decisions will affect their own staff as well as service users. The studies in this issue capture only a couple of dimensions of these effects. Much more research is needed but it is important to keep in mind that we as researchers, as well as policy makers, can open up possibilities; we can also, however, reproduce conditions that foreclose the development of community service models that support peoples' desire to remain active members of their communities as they age.

\section{References}

Aston, T. (1999). The health reforms: To market and back? In J. Boston, P. Dalziel and S. St. John (Eds.), Redesigning the New Zealand welfare state (pp. 134-153). Oxford University Press.

Health Canada. (1998a). Conference on national approaches to pharmacare. Proceedings. January 18-20. Prepared by Karen Graham, Panacea Consulting Inc.

Health Canada. (1998b). National conference on health info-structure. Final Report. February 8-10. Prepared by Marc Lee.

Health Canada. (1998c). National conference on home care: Proceedings. March 8-10. Prepared by Helen Patriquin of the Nova Scotia Association of Health Organizations. 
Neysmith, S. (1995). Would a national information system promote the development of a Canadian home and community care policy? An examination of the Australian experience. Canadian Public Policy-Analyse de Politiques, 31(2), $159-173$.

Shapiro, E. (1997). The cost of privatization: A case study of home care in Manitoba. Winnipeg: Canadian Centre for Policy Alternatives.

Sheila M. Neysmith (Auckland, N.Z., February 1999) 